\title{
RELATIVE CONVEXITY AND QUADRATURE RULES FOR THE RIEMANN-STIELTJES INTEGRAL
}

\author{
PETER R. MERCER
}

Abstract. We develop Trapezoid, Midpoint, and Simpson's rules for the Riemann-Stieltjes integral, the latter two being new. These rules are completely natural when the notion of relative convexity is used.

Mathematics subject classification (2010): 65D30.

Keywords and phrases: trapezoid rule, midpoint rule, Simpson's rule, Riemann-Stieltjes integral, relative convexity, Hadamard's inequality.

\section{REFERENCES}

[1] S. D. Conte \& C. DE Boor, Elementary Numerical Analysis: An Algorithmic Approach, 3rd edition, McGraw-Hill, 1980.

[2] T. K. Boehme, W. Preuss \& V. VAN DER WALL, On a simple numerical method for computing Stieltjes integrals in reliability theory, Prob. in Eng. \& Inf. Sci. 5 (1991), 113-128.

[3] K. Diethelm, A note on the midpoint rectangle formula for Riemann-Stieltjes integrals, J. Stat. \& Com. Simul. 74 (2004), 920-922.

[4] S. S. DRAGOMIR, Some inequalities of midpoint and trapezoid type for the Riemann-Stieltjes integral, Nonlinear. Anal. 47 (2001), 2333-2340.

[5] M. Tortorella, Closed Newton-Cotes quadrature rules for Stieltjes integrals and numerical convolution of life distributions, SIAM J. Sci. Stat. Comp. 11 (1990), 732-748.

[6] M. TORTORElla, Numerical solutions of renewal-type integral equations, INFORMS J. Comp. 17 (2005), 66-74.

[7] M. XIE, W. PREUSS \& L. R. CUI, Error analysis of some integrations procedures for renewal equations and convolution integrals, J. Stat. \& Comp. Simul. 73 (2003), 59-70.

[8] P. R. MERCER, Hadamard's inequality and trapezoid rules for the Riemann-Stieltjes integral, J. Math. Anal. Appl. 344 (2008), 921-926.

[9] C. Niculescu \& L. E. Persson, Convex Functions and their Applications, CMS Books in Mathematics, Springer, 2006. 